\title{
ESTUDO DE COMPOSTOS INTERMETÁLICOS DE Au - Al, OBTIDOS POR DIFUSÃO NO ESTADO SÓLIDO, USANDO A MICROSCOPIA ELETRÔNICA DE VARREDURA (MEV)
}

\author{
A. S. S NEVES ${ }^{1}$, L. M. M. DIAS ${ }^{2}$, M. V. R. da $\operatorname{SILVA}^{3}$, F. A. de $\mathrm{SÁ}^{4}$, J. A. S. SOUZA ${ }^{5}$ \\ 1,2,3,4,5 Universidade Federal do Pará, Programa de Pós-Graduação em Engenharia de Recursos \\ Naturais da Amazônia \\ E-mail para contato: alacidneves@ufpa.br
}

\begin{abstract}
RESUMO - Utilizando filmes de $\mathrm{Au}$ - Al foram estudados os compostos intermetálicos. formados pela difusão no estado sólido. A Microscopia eletrônica de varredura (MEV) e Energia dispersiva por elétrons secundários (EDS) foram os métodos utilizados para a observação do fenômeno. A amostra de ouro com massa de 0,330 g e pureza de 99,9 \% foi laminada até a espessura de 0,1 mm, sobreposta com papel alumínio com pureza de $99 \%$. Os filmes foram enrolados, tipo rocambole e prensados. Em seguida submetidos a tratamento térmico a 550 ${ }^{\circ} \mathrm{C}$ por 1 hora. O corpo de prova foi resfriado em dessecador por $24 \mathrm{~h}$. O procedimento metalográfico seguiu a norma ASM Handbook, ASM Internation, 2004 de preparação de amostras. A metalografia foi desenvolvida através do embutimento a frio de uma porção de $0,045 \mathrm{~g}$ do corpo de prova em resina acrílica, a qual foi lixada com lixas de grãos abrasivos de número 400, 600, 1200, 1500 e 2000 e polida com alumina.
\end{abstract}

Palavras - chave: Difusão, intermetálico Au - Al, microscopia eletrônica de varredura.

\section{INTRODUÇÃO}

Materiais são submetidos com frequência a tratamentos térmicos para melhorarem suas propriedades mecânicas (Callister; Willian, 2011) da composição química como resultado do movimento dos átomos, ou ocorrência de difusão no estado sólido (Shackelford, 2008).

O processo, no qual os átomos de um metal se difundem para o interior do outro, é conhecido como interdifusão, ou difusão de impurezas. O fenômeno de difusão no estado sólido pode ocorrer quando as barras de dois metais diferentes se unem, de modo que exista um contato íntimo entre as duas fases (Callister; Willian, 2011).

Sob o ponto de vista microestrutural, a fase de um material é uma região que difere da outra no que se refere à estrutura e /ou à composição. Um diagrama de fases é a representação gráfica que indica para diferentes temperaturas, pressões e composições, quais as fases presentes no sistema (ASM, 1992). 
No diagrama de fases ouro - alumínio (Au-Al) mostrado na Figura. 1, há cinco fases de intermetálicos descritas por Hansen identificadas no sistema como $\mathrm{AuAl}_{2}, \mathrm{AuAl}, \mathrm{Au}_{2} \mathrm{Al}$, $\mathrm{Au}_{5} \mathrm{Al}_{2}$ e $\mathrm{Au}_{4} \mathrm{Al}$ (Philofsky, 1970). Somente os compostos $\mathrm{AuAl}_{2}$ e $\mathrm{Au}_{2} \mathrm{Al}$ têm ponto máximo de fusão, enquanto todos os outros formam-se periteticamente (Majni et al., 1981).

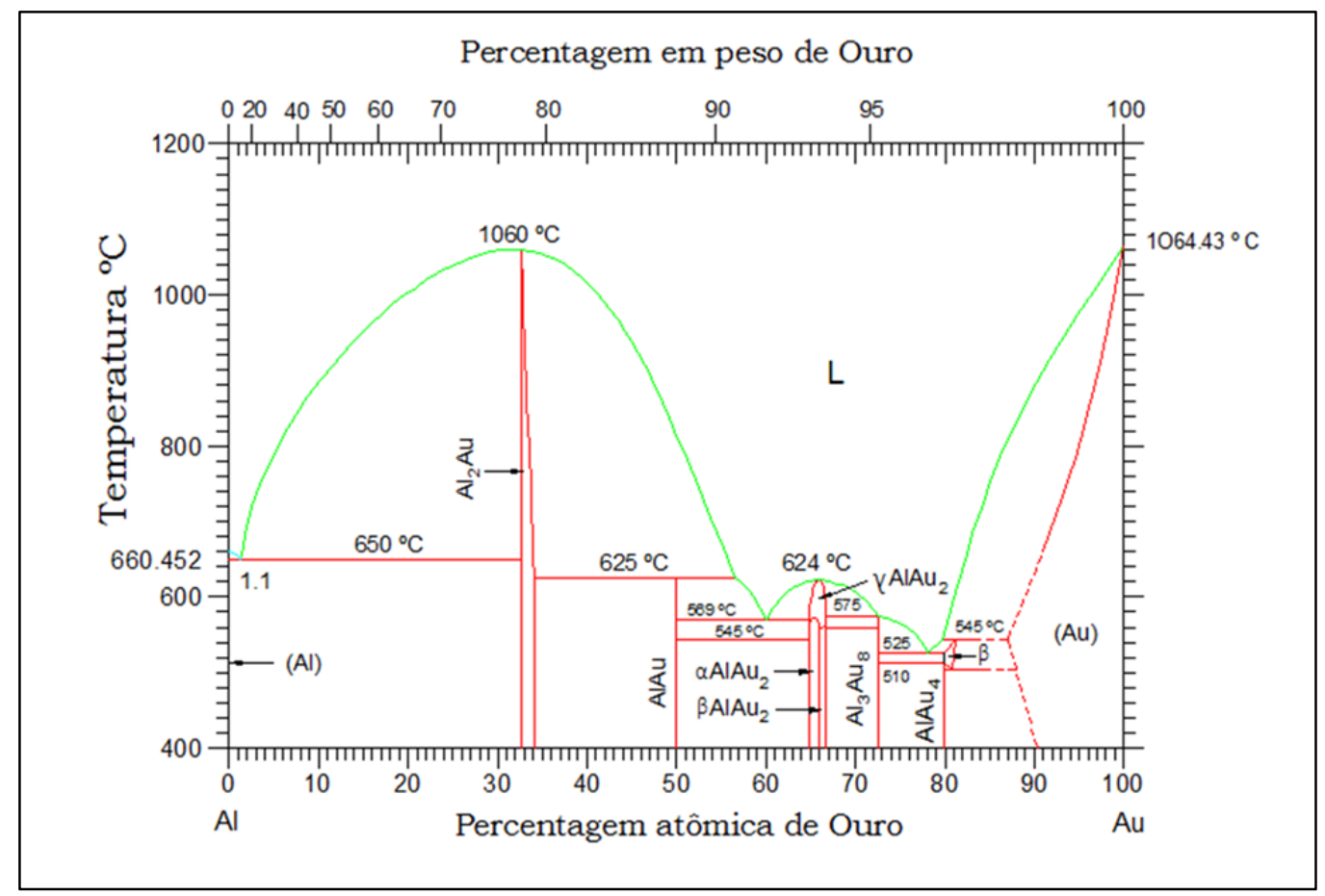

Figura1-Diagrama de fases Au-Al.

Fonte: Adaptado de Murray et al. (1987)

Os intermetálicos são constituídos de dois ou mais elementos metálicos com características particulares e distintas dos metais que os originaram (Leal Neto; Guilherme, 2012).

O ensaio metalográfico realizado em materiais metálicos pode ser macrográfico ou micrográfico, e é abordado através de sua textura que em geral é realizado em uma seção previamente preparada e atacada adequadamente por um reagente químico. A macrografia pode ser observada a olho nu, lupa ou com utilização de microscópios estéreos (que favorecem a profundidade de foco e dão, portanto, visão tridimensional da área observada) com aumentos que podem variar de $5 \mathrm{X}$ a $64 \mathrm{X}$, por seu intermédio tem-se uma ideia do conjunto (ASM, 1992).

Para a visualização da microestrutura de metais, diversas soluções de ataque têm sido utilizadas com a finalidade de identificar as regiões dos contornos de grão, tamanho de grão, microconstituintes, proporção e dispersão de fases, inclusões e micro segregação, que são observadas através da microscopia óptica (MO), microscopia eletrônica de varredura (MEV) e microscopia eletrônica de transmissão (MET) sendo que a identificação quantitativa dos elementos químicos pode ser obtida através da espectroscopia de energia dispersiva (EDS). (Vurobi Junior; Cintho, 2008). 
A difusão intermetálica em sistemas binários Al-Au é de muito interesse devido estes sistemas exibirem propriedades mecânicas adversas e favoráveis. Tais propriedades são particularmente importantes em fabricação de circuito integrado (Fouracre, 1986). Enquanto que as propriedades ópticas são importantes na fabricação de jóias devido a coloração que pode ser obtida através da cobertura de finas camadas de ouro púrpuro, por exemplo, obtidos do composto intermetálico $\mathrm{AuAl}_{2}$ (Supansomboom et al, 2008). Há ainda o interesse do ponto de vista teórico que está relacionado com estudo de estruturas eletrônicas de ligas (Piao et al, 2002).

Neste estudo utilizamos Microscópio de varredura eletrônica (MEV) e Espectroscopia por dispersão de energia (EDS) para a visualização e determinação da composição química de intermetálicos formados pela difusão no sistema binário Au-Al.

\section{MATERIAIS E MÉTODOS}

O estudo iniciou com a laminação da amostra de ouro com certificado de pureza 99,9 \% e espessura de 0,1 mm, que foi sobreposta com filme de alumínio com pureza 99,9 \% e espessura de o,02 mm, a seguir as lâminas foram enroladas estilo rocambole de tal modo que os filmes pudessem ficar intimamente em contato como mostra a Figura 2.1, sendo então submetido à temperatura de $550{ }^{\circ} \mathrm{C}$ em mufla por 1 hora e após este período foi resfriado em dessecador por 24 horas.

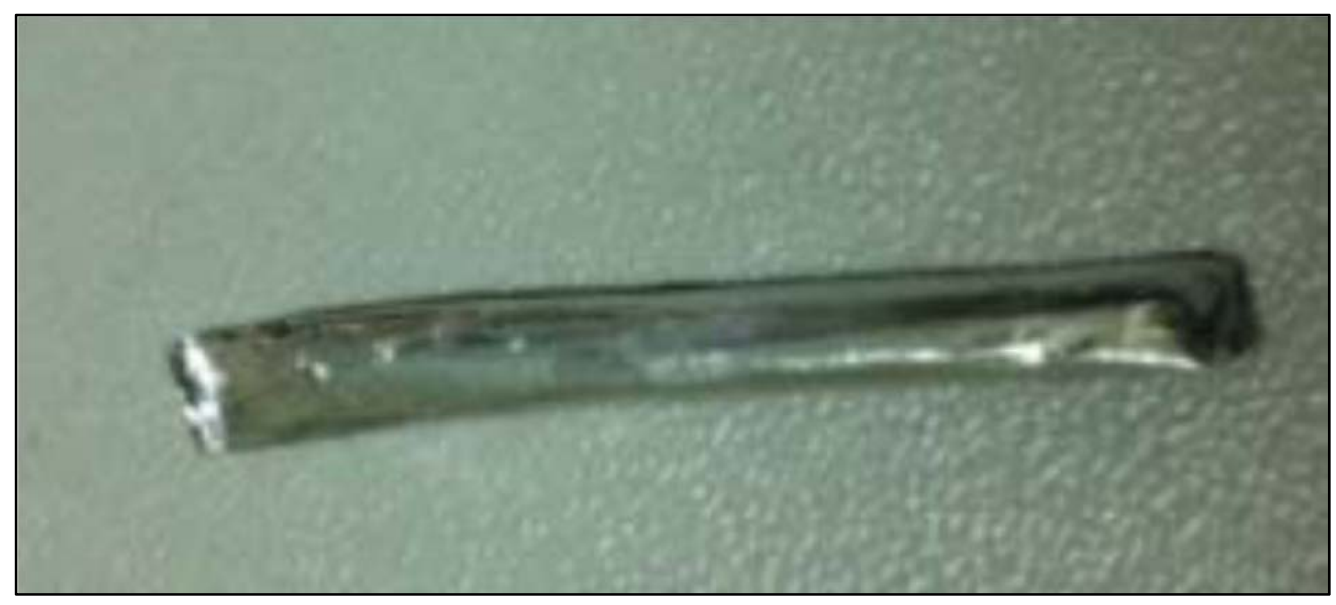

Figura 2.1 - Rocambole das lâminas ouro e alumínio Fonte: Acervo próprio

Para o ataque colorido na amostra 1 , foi utilizado uma solução de Iodeto de potássio e Iodo sublimado, com tempo de contato de 40 segundos, conforme a norma ASM Handbook.

Para o ataque químico na amostra 2 foi utilizado água régia que é uma solução de ácido clorídrico e ácido nítrico na proporção 3:2, com tempo de contato de 40 segundos, conforme a norma ASTM E 407-07, indicado para ligas a partir de 90\% de ouro. 


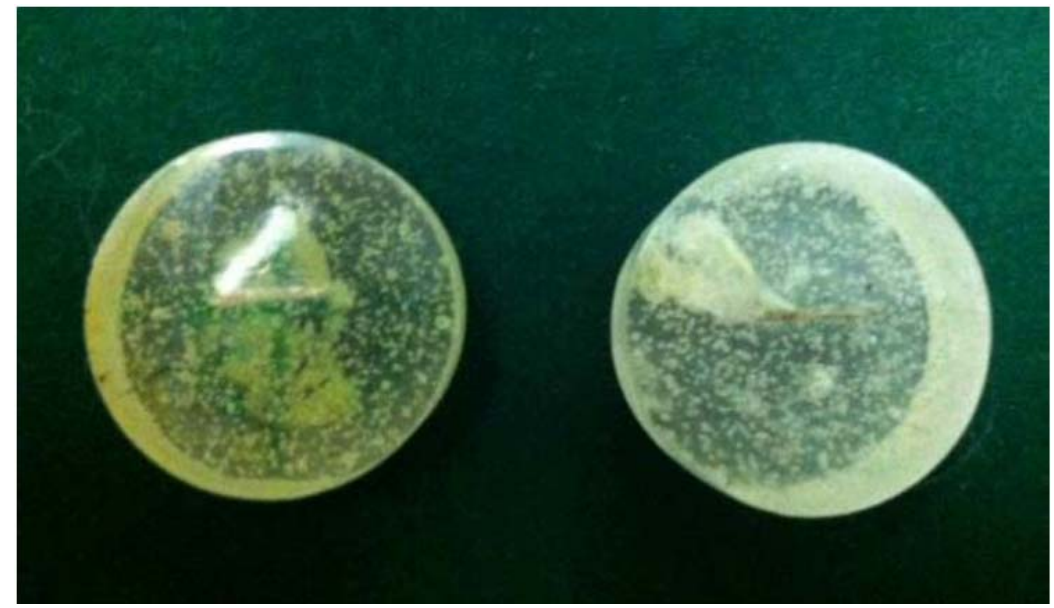

Figura 2.2 - Embutimento da Amostras 1 e Amostra 2.

Fonte: Acervo próprio

As regiões de difusão das amostras foram identificadas utilizando os seguintes dispositivos: microscopia eletrônica de varredura (MEV), e a identificação quantitativa dos elementos químicos foi obtida através da espectroscopia de energia dispersiva (EDS).

\section{RESULTADOS E DISCUSSÕES}

As Figuras 3.1 (amostra 1) e Figuras 3.2 (amostra 2), mostram as micrografias eletrônicas obtidas do MEV que indicam os filmes de ouro (na cor branco) e alumínio (na cor cinza) após o tratamento metalográfico. A amostra 1 sofreu o ataque químico com uma solução de iodo sublimado e iodeto de potássio e a amostra 2 o ataque foi com água régia. Com relação ao ataque químico foi observado que não se visualizou os contornos de grãos e as diferenças nas fases microestruturais.

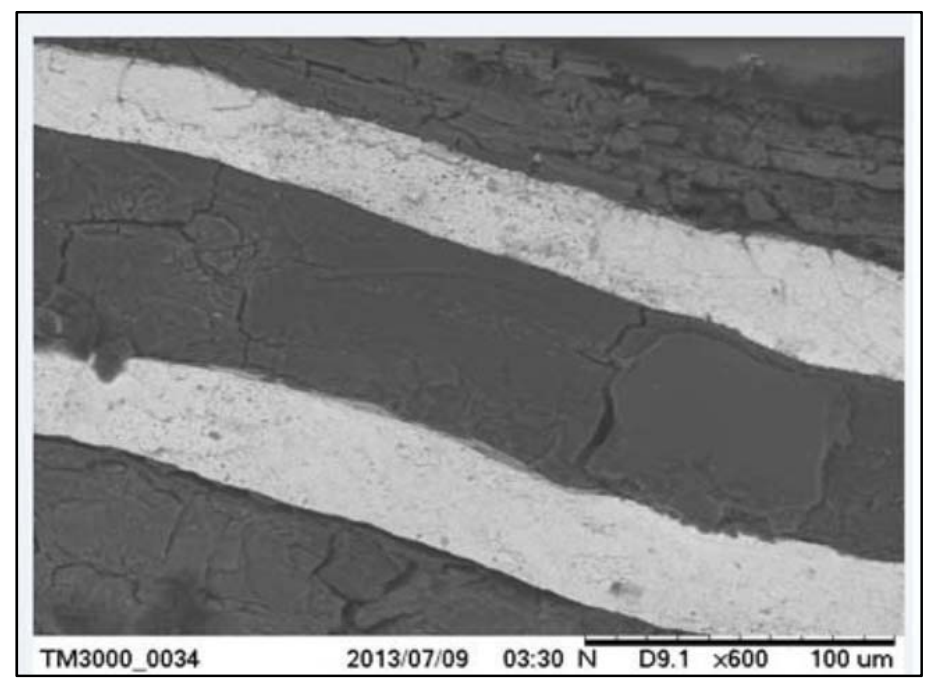

Figura 3.1 - Micrografia dos filmes $\mathrm{Au}-\mathrm{Al}$ da amostra 1 após ataque químico. 


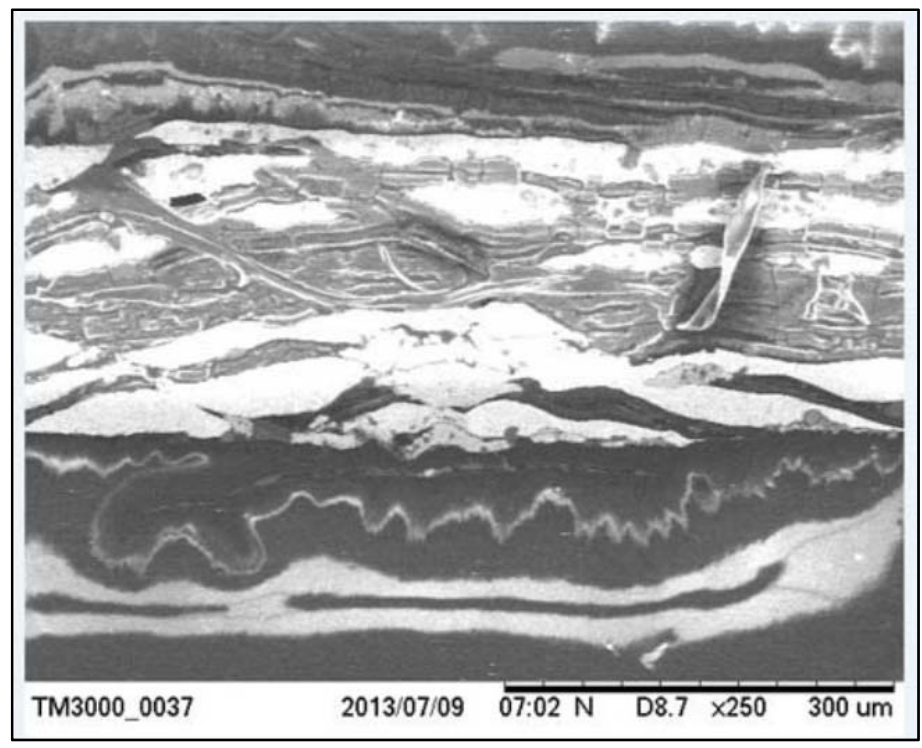

Figura 3.2 - Micrografia dos filmes Au-Al da amostra 2 após ataque químico.

A Figura 3.3 é composta pela micrografia obtida por MEV e pelo espectro do ponto obtido por EDS da amostra 1 localizado próximo da superfície de contato. Os picos apresentados no EDS indicam teores de alumínio e ouro, sugerindo a ocorrência da difusão do alumínio no ouro. Os valores dos percentuais em peso foram: 18,624 de C; 24,531 de O; 4,402 de $\mathrm{Al}$ e 52,452 de ouro. Os picos de carbono e oxigênio que aparecem no espectro são da resina utilizada no embutimento, portanto são desconsiderados. Desse modo, temos que as massas do ouro e alumínio nos picos encontrados para este ponto representam $100 \%$, sendo $62 \%$ de ouro e $38 \%$ de alumínio.

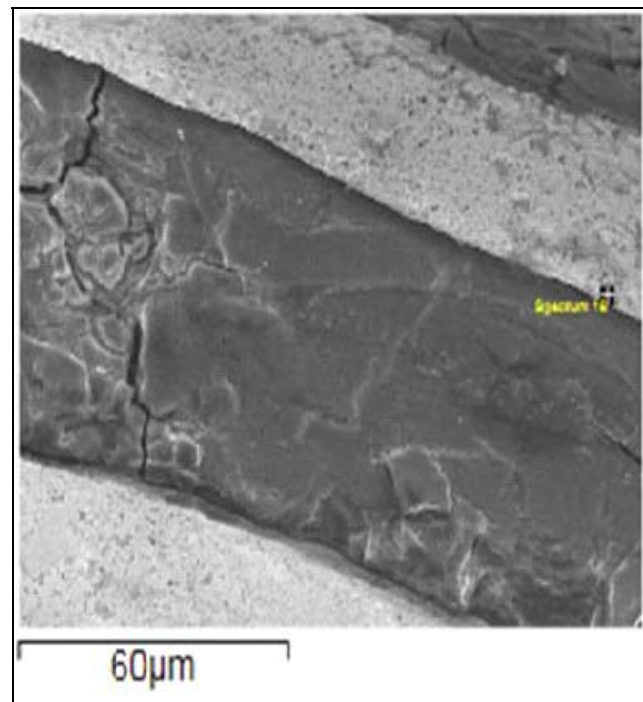

Figura 3.3 - Micrografia (MEV) e Espectro do EDS do Au-Al (amostra 1) próximo da superfície de contato

A Figura 3.4 é composta pela micrografia obtida por MEV e pelo espectro do ponto obtido por EDS da amostra 1 localizado em um ponto afastado das superfícies de contato. O espectro de EDS apresentou somente picos significativos de ouro, o que demonstra que não 
houve difusão do alumínio no ouro na região mais afastada das fronteiras de contato entre os filmes.
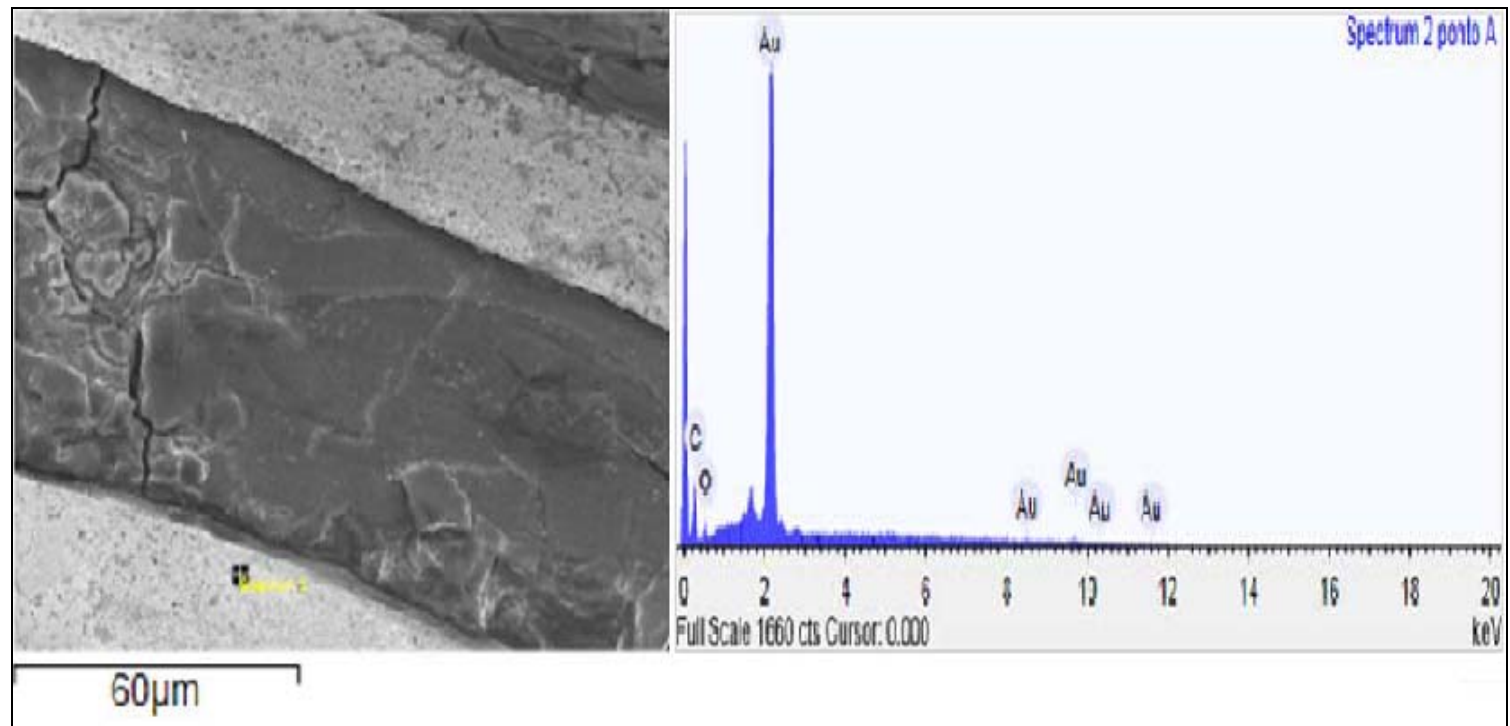

Figura 3.4 - Micrografia do Au-Al (MEV) e Espectro do EDS do Au-Al (amostra 1) afastado da superfície de contado.

A Figura 3.5 é composta pela micrografia obtida por MEV e pelo espectro do ponto obtido por EDS da amostra 2. Os resultados percentuais em peso foram: 56,156 de C; 8,465 de $\mathrm{O}, 2,138$ de $\mathrm{Al}$ e 33,241 de Au. Os picos de carbono e oxigênio que aparecem no espectro são da resina utilizada no embutimento, portanto, assim como nas amostras anteriores também foram desconsiderados. Desse modo, temos que as massas do ouro e alumínio nos picos encontrados neste ponto representam 100\%, sendo 67\% de ouro e 33\% de alumínio.

Do mesmo modo que na amostra 1 o teor de alumínio captado pelo EDS mostra que houve difusão do alumínio no ouro.

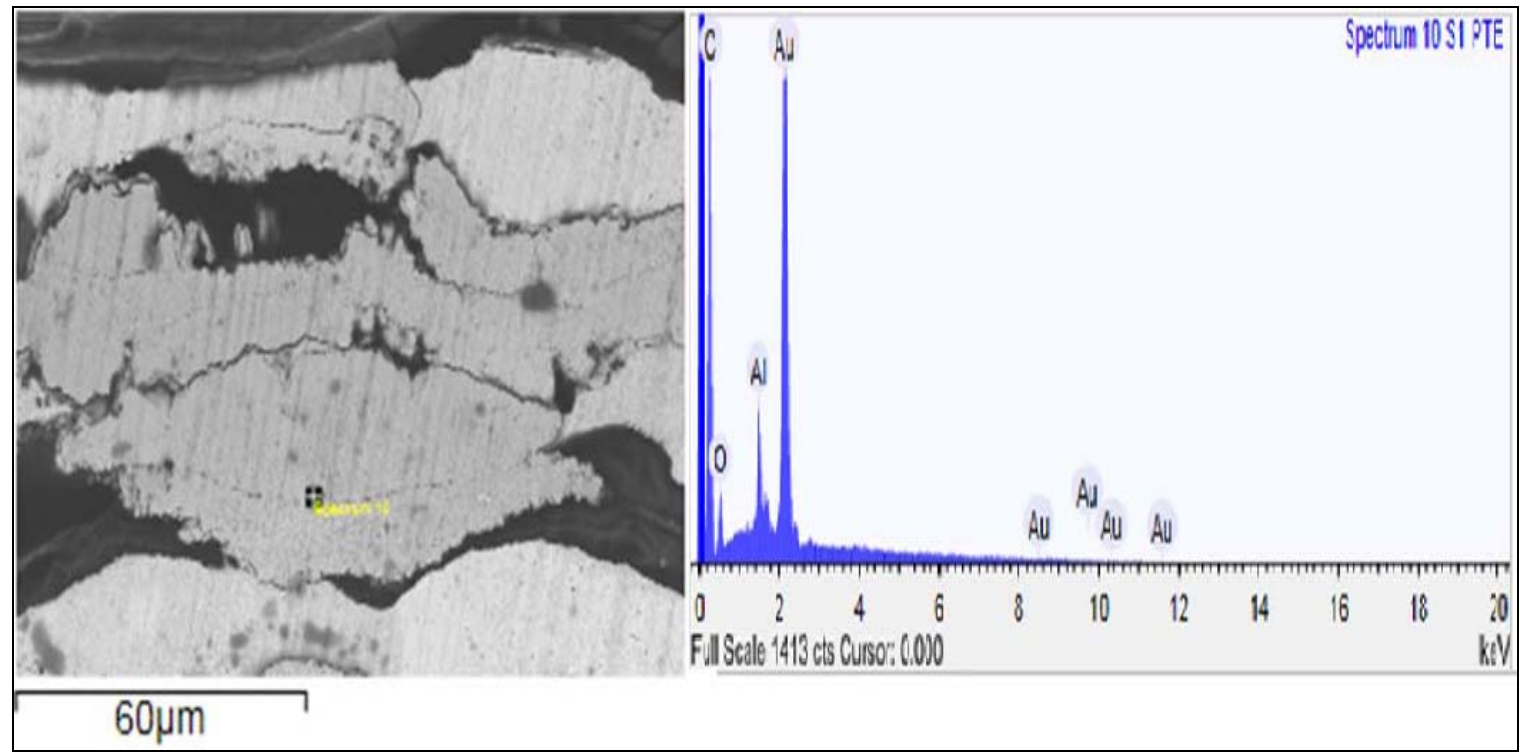




\section{CONCLUSÃO}

Os resultados do estudo metalográfico mostram que houve difusão do alumínio no ouro. A difusão do alumínio no ouro, nas amostras 1 e 2, demonstrou que o fenômeno ocorreu principalmente nas fronteiras de contato entre os filmes e não em toda a superfície do ouro.

As análises realizadas pela Espectroscopia de energia dispersiva (EDS), nos pontos selecionados em que ocorreu a difusão entre o alumínio e ouro, apresentaram picos que indicam a formação de compostos intermetálicos.

A técnica metalográfica utilizada neste estudo não possibilitou a retirada de informações da sua microestrutura, isto pode ter ocorrido devido ao tempo de contato da solução de ataque com a amostra não ter sido suficiente para revelar as regiões dos contornos de grão e tamanho de grão.

\section{REFERENCIAS}

ASM- AMERICAN SOCIETY FOR METALS, Handbook - Alloy phases diagrams ASM International, v.3,1992

ASTM STANDARD E3-11 - Standard Guide for Preparation of Metallografic Specimens.American Society for Testing and Materials, 2011.

ASTM STANDARD E407-07 - Standard Guide for Microetching Metals and Alloys.American Society for TestingandMaterials, 2007.

CALLISTER, Jr; WILLIAN,D. Fundamentos da ciência e engenharia de materiais. Rio de Janeiro: LTC, 2011.

FOURACRE, R. A. Electron Microscope Observations of chemical diffusion in the $\mathrm{Al} / \mathrm{Au}$ system.ThinSolidsFilms, p. 135,1986.

LEAL NETO, R. M.; GUILHERME, E. G. Elaboração mecânica de ligas de ouro colorido por moagem de alta energia. $67^{\circ}$ Congresso Abm- International. Rio de Janeiro, 2012.

MAJNI, C. et al. Gold-aluminum thin-film interactions and compound formation.J.Appl. Phys. p.52(6), June, 1981.

MURRAY, J. L et al. The Al - Au (Aluminum - Gold) system. Bulletin of Alloy Phase Diagrams. v. 8, n 1, p. 20-30, 1987.

PHILOFSKY, ELLIOT. Intermetallic formation in gold-aluminum systems.Solid-State Electronics.1970)

PIAO et al. Electronic structures of Au-Al thin-films alloys by high energy XPS and XANES.Journal of Electron Spectroscopy, p. 125, 2002. 
SHACKELFORD, JAMES F. Ciência dos Materiais.6aed. SP: Pearson Prentice Hall, 2008. 